\title{
Hydrodynamic cavitation in micro channels with channel sizes of 100 and 750 micrometers
}

\author{
Joost Rooze • Matthieu André • Gert-Jan S. van der Gulik • David Fernández-Rivas • \\ Johannes G. E. Gardeniers $\cdot$ Evgeny V. Rebrov $\cdot$ Jaap C. Schouten · \\ Jos T. F. Keurentjes
}

Received: 18 May 2011 / Accepted: 22 July 2011/Published online: 26 October 2011

(c) The Author(s) 2011. This article is published with open access at Springerlink.com

\begin{abstract}
Decreasing the constriction size and residence time in hydrodynamic cavitation is predicted to give increased hot spot temperatures at bubble collapse and increased radical formation rate. Cavitation in a $100 \times 100 \mu \mathrm{m}^{2}$ rectangular micro channel and in a circular $750 \mu \mathrm{m}$ diameter milli channel has been investigated with computational fluid dynamics software and with imaging and radical production experiments. No radical production has been measured in the micro channel. This is probably because there is no spherically symmetrical collapse of the gas pockets in the channel which yield high hot spot temperatures. The potassium iodide oxidation yield in the presence of chlorohydrocarbons in the milli channel of up to $60 \mathrm{nM} \mathrm{min}{ }^{-1}$ is comparable to values reported on hydrodynamic cavitation in literature, but lower than
\end{abstract}

J. Rooze · J. C. Schouten $(\bowtie)$ - J. T. F. Keurentjes

Laboratory of Chemical Reactor Engineering, Eindhoven

University of Technology, PO Box 513, 5600 MB Eindhoven,

The Netherlands

e-mail: j.c.schouten@tue.nl

M. André · G.-J. S. van der Gulik

Bunova Development BV, PO Box 1072, 8001 BB Zwolle,

The Netherlands

Present Address:

M. André

Thermo Fluids Lab, George Washington University, 801 22nd street NW, Washington, DC 20052, USA

D. Fernández-Rivas · J. G. E. Gardeniers

Mesoscale Chemical Systems Group, MESA+ Research

Institute, University of Twente, PO Box 217,

7500 AE Enschede, The Netherlands

E. V. Rebrov

School of Chemistry and Chemical Engineering,

Queen's University Belfast, Belfast BT9 5AG, UK values for ultrasonic cavitation. These small constrictions can create high apparent cavitation collapse frequencies.

Keywords Hydrodynamic cavitation - Microfluidics . Chlorohydrocarbons · Radicals · CFD

\section{Introduction}

Cavitation is the growth and collapse of a gas bubble in a liquid (Leighton 1994). The characteristic collapse time is much shorter than the characteristic time for heat transfer. High temperatures and pressures are therefore reached inside the bubble due to compression (Didenko and Suslick 2002; Rae et al. 2005). Estimations for the temperature and pressure during a collapse in ultrasound are generally around several 1,000 K (McNamara et al. 1999; Hilgenfeldt et al. 1999) and several hundred bar (Kamath et al. 1993). Applications of cavitation are e.g. making surface modifications (Suslick and Price 1999), creating radical species (Mason 1990), or mixing liquids (Marmottant et al. 2006). The energy of the collapse is dissipated after the event, and the average liquid temperature stays at ambient values. Common ways to create cavitation are with ultrasound, in a hydrodynamic flow field, and with a focussed laser burst. The pressure in a flow field decreases between a point before a constriction (1) and inside a constriction (2), and is described by Bernoulli's equation:

$p_{1}-p_{2}=\frac{1}{2} \rho\left(v_{2}^{2}-v_{1}^{2}\right)$

where $p$ is the pressure, $\rho$ is the liquid density, and $v$ is the liquid velocity. A cavitation bubble is generated when the pressure decreases to a sufficiently low value to generate growth of an existing gas pocket in the liquid. 
The dimensionless cavitation number $(\mathrm{CN})$ is often used to characterise cavitation:

$C N=\frac{p_{\text {ref }}-p_{v}}{\frac{1}{2} \rho v_{c}^{2}}$

where $p_{\text {ref }}$ is the reference pressure, often the downstream pressure, $p_{\mathrm{v}}$ is the liquid vapour pressure, and $v_{c}$ is the liquid velocity inside the constriction. The $\mathrm{CN}$ is the ratio between the static pressure and the pressure drop due to the flow through the constriction. Theoretically, the liquid velocity is sufficient to start forming vapour at $\mathrm{CNs}$ below 1 . Nuclei already present in the liquid can grow under these conditions. However, the experimental $\mathrm{CN}$ value at inception depends on constriction size and geometry. Cavitation starts at CNs of $1-7$ in constrictions with diameters of $1.5-3 \mathrm{~cm}$ in a $3.8-\mathrm{cm}$ diameter pipe (Yan and Thorpe 1990). It starts at CNs of $0.1-0.5$ in $10 \times 100$ to $40 \times 100 \mu \mathrm{m}^{2}$ constrictions in $100 \times 100 \mu^{2}$ channels (Mishra and Peles 2005c; Singh and Peles 2009). Since the $\mathrm{CN}$ is not consistent for different geometries, pressures and velocities have been provided instead in this article when known.

Ultrasound-induced cavitation is regarded as the most energy efficient process for radical formation (Suslick et al. 1997; Braeutigam et al. 2009; Franke et al. 2010). Ultrasonic cavitation at $850 \mathrm{kHz}$ has a 14 times higher breakdown efficiency of aromatic compounds than hydrodynamic cavitation (Braeutigam et al. 2009). However, several authors report that hydrodynamic cavitation (HC) has a higher energy efficiency (Gogate et al. 2001; Gogate 2010; Kalamuck and Chahine 2000). These studies use ultrasonic cavitation processes at ultrasound frequencies around $20 \mathrm{kHz}$, whereas the optimum radical production frequency is found around $300 \mathrm{kHz}$ (Wayment and Casadonte 2002; Beckett and Hua 2001).

Decreasing the constriction diameter in hydrodynamic cavitation is desirable because this decreases pressure recovery time and increases the intensity of the cavitation bubble collapse. This results in increased temperatures and radical formation rates (Arrojo and Benito 2008; Braeutigam et al. 2010; Amin et al. 2010). Micro fabrication technology offers high precision manufacturing of channels with dimensions in the micrometer range. These channels are easily studied and have small constrictions compared to previous and recent work in hydrodynamic cavitation (Braeutigam et al. 2010; Gogate et al. 2001). It has been shown that by a miniaturisation strategy in sonochemical reactors it is possible to study complex phenomena such as microbubble nucleation and improve operation efficiency (Fernandez Rivas et al. 2010). The relatively smooth silicon surfaces used there allowed the control of certain cavitation conditions.
In this work, cavitation in constrictions with an area of $20 \times 100 \mu^{2}$ in channels of $100 \times 100 \mu \mathrm{m}^{2}$ and constrictions of 100-300 $\mu \mathrm{m}$ diameter in tubes with a diameter of $750 \mu \mathrm{m}$ has been investigated. Cavitation behaviour at various flow rates has been studied in channels at both size scales. Pressure gradients and void fractions in the fluid have been obtained by computational fluid dynamics (CFD) modelling. These pressure gradients have been used to calculate the temperature of a bubble collapse using the Rayleigh-Plesset equation. Apparent frequencies for bubbles travelling through constrictions with a $200 \mu \mathrm{m}$ diameter are of the same order of magnitude as frequencies in ultrasonic cavitation for the milli channel $(160 \mathrm{kHz})$. Estimations of the collapse temperature are compared with the results on an oxidation reaction carried out by cavitation in the milli channel. This is the first time that radical production rate measurements of hydrodynamic cavitation at these length scales are carried out according to our knowledge.

\section{Experimental}

\subsection{Micro channel experiments}

The micro channel design was similar to that of Mishra and Peles (2005a), see Fig. 1. The channel and pressure ports geometry were etched on the top side of the double side polished silicon wafers $n$-type $\{100\}$ using a deep reactive ion etching process. The pressure port openings, and the inlet and outlet ports were machined on the back side. The top wafer was made of borofloat glass to allow visual inspection. The channel width and depth was $100 \mu \mathrm{m}$, and its total length was $1 \mathrm{~cm}$. The constriction width and length was 20 and $10 \mu \mathrm{m}$, respectively. A liquid flow rate of 0.5-6.5 mL min ${ }^{-1}$ was created with a JASCO PU 2086

(a)
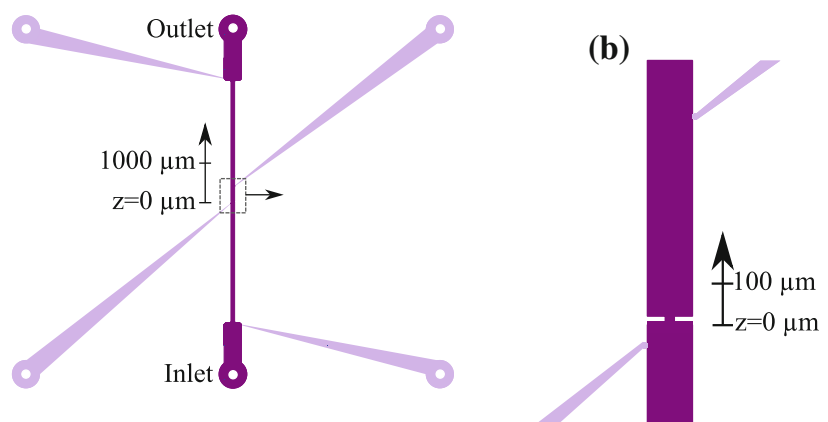

Fig. 1 Schematic top view representation of the channel layout, a entire channel, $\mathbf{b}$ magnification of the constriction. The main channel with the constriction is in the center (dark colour). The diagonal channels are connected to pressure sensors or dead ends (light colour) 
Plus pump with a filter with $1 \mu \mathrm{m}$ pores between the pump and the micro channel. The pressure was measured relative to the atmospheric pressure at $460 \mu \mathrm{m}$ downstream of the constriction using a calibrated Sensortechnics sensor, 24PC series 0-16 bar. An Olympus IX-71 microscope with an Olympus UplanFLN $10 \times$ lens and a Redlake X4 high speed camera was used for visualisation, using a Nikon SB900 flash light at full flash length as an illumination source. The exposure time was $1 \mu$ s for one frame. MilliQ water was used in visualisation studies. MilliQ water $(20 \mathrm{~mL})$ containing $0.1 \mathrm{M} \mathrm{KI}$ (p.a., Merck) and saturated with $\mathrm{CH}_{2} \mathrm{Cl}_{2}$ (p.a., Sigma-Aldrich) was used in radical production experiments. The chloroalkane was added to increase the radical production (Chakinala et al. 2008). Saturation with argon was done during 30 min prior to the experiment. The solution was kept under argon atmosphere during the experiment. The production of $\mathrm{I}_{3}^{-}$was measured at the experiment start, and after 60 min using a Shimadzu 2501-PC UV spectrometer operated at $350 \mathrm{~nm}$. The $\mathrm{I}_{3}^{-}$ concentration was calculated using a spectroscopic extinction coefficient of $26.4 \times 10^{3} \mathrm{~L} \mathrm{~mol}^{-1} \mathrm{~cm}^{-1}$ (Palmer et al. 1984).

\subsection{Milli channel experiments}

A poly(ether ether ketone) (PEEK) capillary with an internal diameter of $750 \mu \mathrm{m}$ was inserted in a poly(methyl methacrylate) (PMMA) holder with a constriction of either 110 or $180 \mu \mathrm{m}$ diameter in visualisation studies (see Fig. 2). The transparent PMMA holders with a constriction allow visual

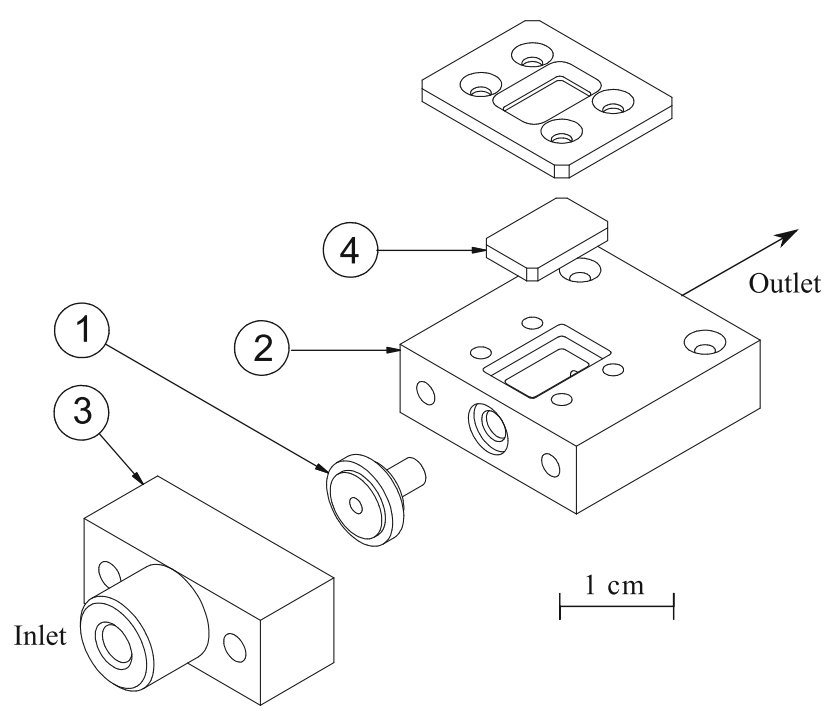

Fig. 2 Schematic drawing of the milli channel assembly. A holder with the constriction is machined in PMMA or PEEK (1). The rest of the assembly is manufactured in PEEK. The holder is inserted into the chamber (2), and fixed using a second block (3) which contains the inlet port. The top and bottom of the chamber are made of transparent quartz plates (4) for illumination inspection inside the constriction. The PMMA constrictions were slightly skewed due to the machining process, the diameters mentioned were measured at the constriction exit. Visualisation was done using a Redlake X4 high speed camera, a Nikon AF micro Nikkor $60 \mathrm{~mm}$ lens, and a Dedocool CoolT3 $250 \mathrm{~W}$ lamp as an illumination source. The exposure time was $1 \mu$ s for one frame. The exit stream enters a $8 \times 4 \times 5.2 \mathrm{~mm}^{3}$ chamber machined in PEEK with two transparent quartz plates on the top and bottom. A $7-80 \mathrm{~mL} \min ^{-1}\left(v_{c} 5-59 \mathrm{~m} \mathrm{~s}^{-1}\right)$ liquid flow was created by

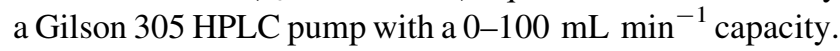
The pressure was measured relative to atmospheric pressure at $2.8 \mathrm{~cm}$ downstream of the constriction using a calibrated Sensortechnics 24PC series 0-16 bar sensor. MilliQ water was used in visualisation studies. PEEK holders with straight 100,200 , and $300 \mu \mathrm{m}$ diameter constrictions were used in radical production experiments. The solution was kept at $20 \pm 1{ }^{\circ} \mathrm{C}$ using a Lauda E300 thermostat. KI solution (20 mL 0.1 M, p.a., Merck) saturated with $\mathrm{CHCl}_{3}$ (p.a., Aldrich) was saturated with argon for $30 \mathrm{~min}$ prior to the experiment, and was kept under argon atmosphere during the experiment. The production of $\mathrm{I}_{3}^{-}$was measured every $5 \mathrm{~min}$. The power input measured by calorimetry was between 2 and $14 \mathrm{~W}$ depending on the flow rate.

\section{Modelling}

\subsection{CFD modelling with simplified Rayleigh-Plesset} model

All channel geometries have been modelled and meshed with ICEM Hexa release 11.0.1 software. They have been spatially discretised using a structured hexa mesh (see Table 1). Only a quarter of the channel has been modelled due to the presence of two symmetry planes. Several refinements have been modelled in order to evaluate the grid dependency. The channels have a refined mesh in the constriction (see Fig. 3) because most vapour is formed in the constriction.

The steady state flow field has been obtained using the CFD software ANSYS CFX release 11.0. This software solves the time averaged Reynolds Averaged Navier Stokes equations (RANS). The closure of the equation system has been realised with a shear stress transport (SST) turbulence model with an automatic near-wall treatment (Esch and

Table 1 Relevant geometry and mesh details used in CFD modelling of the hydrodynamic cavitation devices

\begin{tabular}{lll}
\hline Geometry & Nodes $(1000 \times)$ & Max. aspect ratio \\
\hline Micro channel & 284 & 11.5 \\
Milli channel & 534 & 29 \\
\hline
\end{tabular}



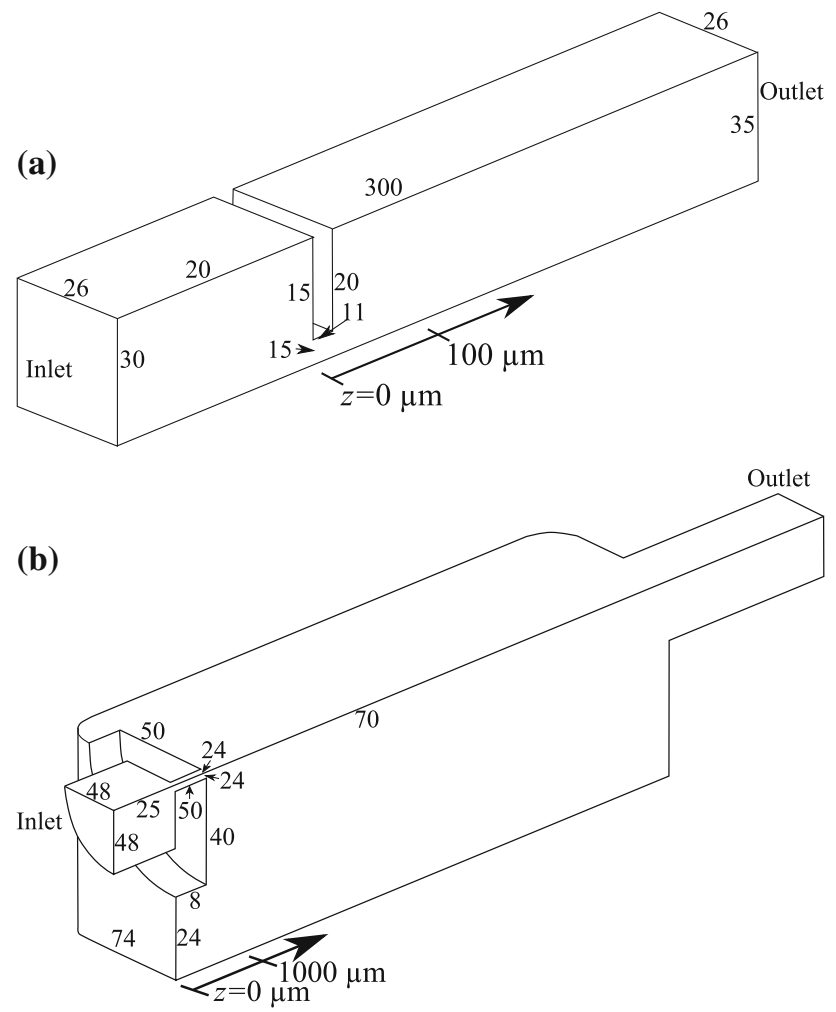

Fig. 3 Quarter mesh geometries of a the micro channel (symmetry plane at the bottom and right of the image) and $\mathbf{b}$ the milli channel (symmetry planes at the top and right of the image). The number of nodes for each boundary are indicated in the image

Menter 2003). The cavitation model is a homogeneous interphase mass transfer model derived from a first order simplification of the Rayleigh-Plesset equation (Also see Eq. 7). It describes the radial dynamics of vapour bubbles of uniform size. The bubble nuclei are assumed to be homogeneously distributed in the liquid. A threshold pressure for cavitation is added to match the pressure drop found in experiments and literature (Mishra and Peles 2005c).

$\dot{R}=\sqrt{\frac{2}{3} \frac{p_{v}-p[t]}{\rho_{l}}} \operatorname{sgn}\left(p_{\text {thresh }}-p[t]\right)$

$\operatorname{sgn}(x)= \begin{cases}0, & x<0 \\ 1, & x \geq 0\end{cases}$

where $p_{\mathrm{v}}$ is the vapour pressure, $p[t]$ is the pressure as a function of time, $\rho_{l}$ is the liquid density, $p_{\text {thresh }}$ is the threshold pressure for growth of the cavitation bubbles. Average vapour fractions are calculated from the total bubble volume. Vaporisation and condensation rates at the bubble interface were described using:

$\dot{m}_{\text {vap }}=3 F_{\text {vap }} \epsilon_{0}(1-\epsilon) \rho_{g} \frac{\dot{R}}{R}$
Table 2 Empirical factors used in the CFD modelling

\begin{tabular}{lll}
\hline Parameter & Value & Dimension \\
\hline$F_{\text {cond }}$ & 0.01 & - \\
$F_{\text {vap }}$ & 50 & - \\
$\alpha_{0}$ & $5 \times 10^{-4}$ & - \\
$R_{0}$ & $1 \times 10^{-6}$ & $\mathrm{~m}$ \\
$p_{\text {thresh }}$ & -0.75 & bar \\
\hline
\end{tabular}

$\dot{m}_{\text {cond }}=3 F_{\text {cond }} \varepsilon \rho_{g} \frac{\dot{R}}{R}$

where $\dot{m}$ is the mass accumulation in time, and where the empirical factors $F_{\text {cond }}$ and $F_{\text {vap }}$ and the initial void fraction $\varepsilon_{0}$ shown in Table 2 were used. The value of $p_{\text {thresh }}$ was chosen to match the Blake threshold criterion (Leighton 1994) for bubbles with an initial radius $R_{0}$ of $1 \mu \mathrm{m}$. The mass, momentum, and void fraction equations were solved in a coupled manner to improve convergence. RMS values for mass and momentum were well below $1 \times 10^{-4}$ and imbalances below $1 \%$.

These equations omitted second order terms in the Rayleigh-Plesset equation. Therefore, a full RayleighPlesset description was solved separately using the pressure gradients obtained from the CFD calculations as an input (Alehossein and Qin 2007).

\subsection{Full Rayleigh-Plesset model}

The radius $R$, pressure $p$, and temperature $T$ of an oscillating bubble under influence of a pressure field has been modelled with a Rayleigh-Plesset equation (Hilgenfeldt et al. 1999).

$$
\begin{gathered}
\rho_{l}\left(R \ddot{R}+\frac{3}{2} \dot{R}^{2}\right)=p_{g}-p[t]-p_{0}+\frac{R}{c_{l}} \dot{p}_{g} \\
-4 \eta_{l} \frac{\dot{R}}{R}-\frac{2 \sigma}{R} \\
\dot{p}_{g}=-\gamma(\mathrm{Pe}) \frac{3 R^{2} \dot{R}}{R^{3}-h^{3}} p_{g} \\
\dot{T}=-(\gamma(\mathrm{Pe})-1) \frac{3 R^{2} \dot{R}}{R^{3}-h^{3}} T-\alpha_{g} \frac{T-T_{0}}{R^{2}}
\end{gathered}
$$

The Péclet number, Pe, is defined as $\frac{R|\dot{R}|}{\alpha_{g}}, c_{l}$ is the speed of sound in the liquid, $1,500 \mathrm{~ms}^{-1}, \eta_{l}$ is the liquid viscosity at $298 \mathrm{~K}, 0.00089 \mathrm{~Pa} \mathrm{~s}, \sigma$ is the liquid surface tension, $0.072 \mathrm{~N} \mathrm{~m}^{-1}$, and $h$ is the minimum bubble radius, $R_{0} /$ 8.84 for argon (Löfstedt et al. 1995). The adiabatic factor $\gamma$ is dependent upon the Péclet number:

$\gamma(\mathrm{Pe})=1+\left(\gamma_{0}-1\right) \exp \left(\frac{-5.8}{\mathrm{Pe}^{0.6}}\right)$ 
where $\gamma_{0}$ is the initial adiabatic factor, 1.67 for argon. This model assumes spherical symmetry of the bubbles during their lifetime. This assumption does not hold for most bubbles in a vapour cloud created by hydrodynamic cavitation. Furthermore, there are no equations for vapour mass transport near the bubble wall. An increased amount of vapour decreases the hot spot temperature. The hot spot temperatures obtained in experiments are therefore lower.

\section{Results and discussion}

\subsection{Micro channel}

A pressure drop of 13 bar over the micro channel constriction is obtained in CFD calculations at a flow rate of $4 \mathrm{~mL} \min ^{-1}$. The formation of a vapour phase in the constriction and downstream is shown in Fig. 4b. The model shows a quick transition between a vapour volume fraction below 0.2 downstream at flow rates below $3 \mathrm{~mL} \mathrm{m^{-1 }}$ and cavities with a vapour fraction above 0.8 at flow rates above $3 \mathrm{~mL} \mathrm{~min}^{-1}\left(v_{c} 25 \mathrm{~ms}^{-1}\right)$. This behaviour is linked with the low pressure region extending from the constriction to the channel downstream of the constriction at these flow rates.

The experimental results obtained by Mishra and Peles (2005a, b , c) in micro channels have been reproduced in a set-up without downstream pressure control. The measurements described in this paper are all performed in the developed cavitation regime. A typical image of hydrodynamic cavitation is shown in Fig. 4c. A gas phase is formed near the constriction. The liquid leaves the constriction as a jet. Liquid-gas mixtures are visible as dark regions. The region with the gas-liquid mixture becomes longer as flow rate increases. The gas phase disappears after a length of several channel diameters at a position depending on the flow rate. Part of the jet forms a recirculation loop. Just after the constriction, a stable gas pocket
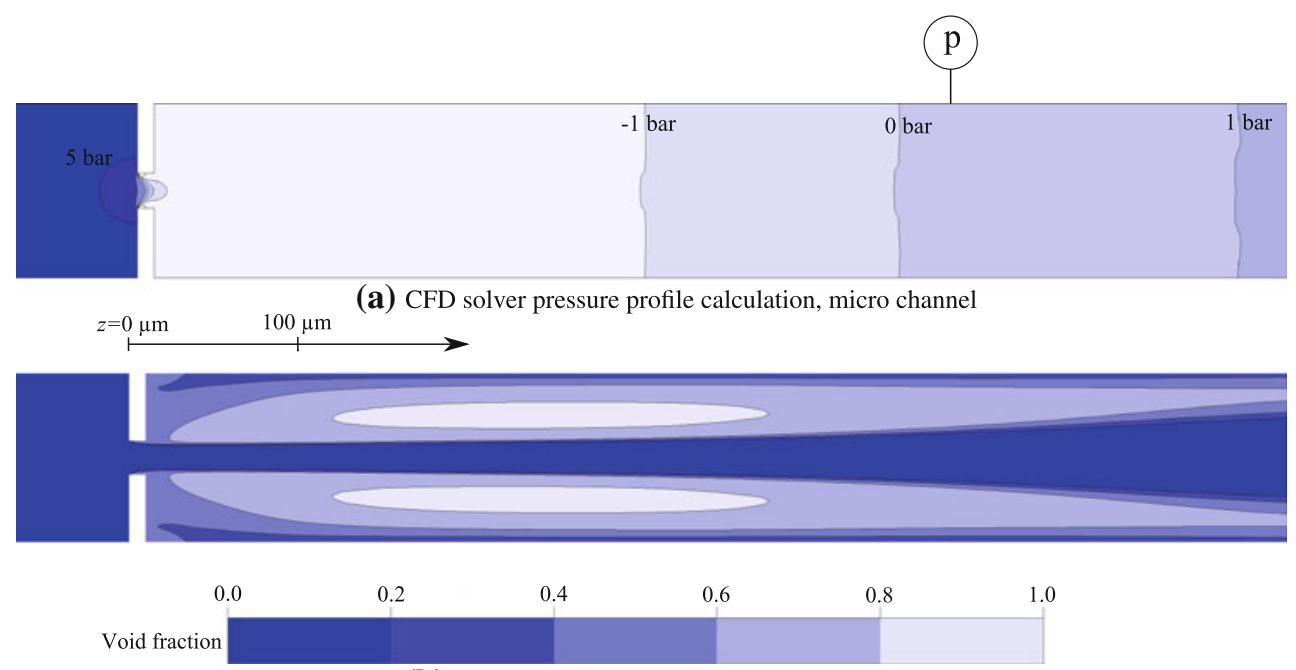

(b) CFD void fraction calculation, micro channel

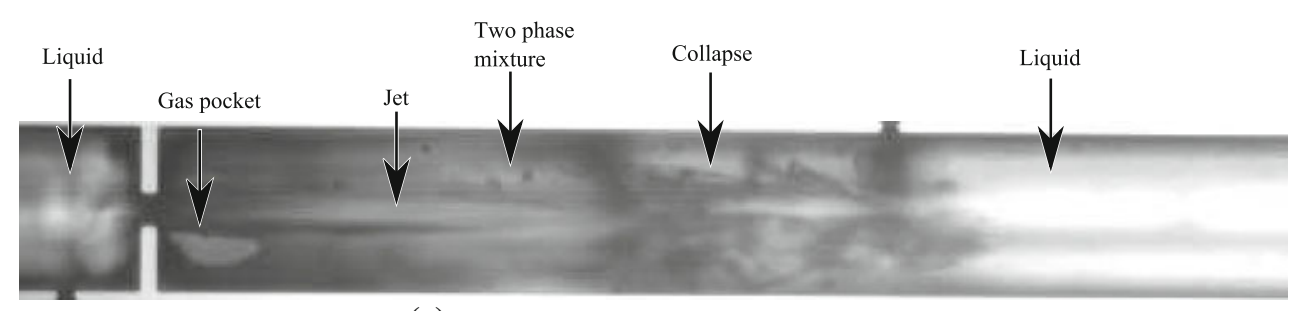

(c) Experimental image, micro channel top view

Fig. 4 Top view of the CFD simulation results solver pressure (a) and void fraction (b) and top view of an experimental image of cavitation (c) in a micro channel with a $20 \times 10 \mu \mathrm{m}$ width and length constriction. A symmetry plane is present in the channel centre, the entire channel is reconstructed using this symmetry plane. Temperature $=25^{\circ} \mathrm{C}, \quad$ Flow $=4 \mathrm{~mL} \mathrm{~min}^{-1}$ (from left to right, $v_{c}=$ $33 \mathrm{~m} \mathrm{~s}^{-1}$ ). The solver pressure drops from 10.8 bar upstream to -2 bar downstream, and increases to the ambient pressure of 1 bar close to the channel exit. A liquid jet in the channel centre, accompanied by a large region with a void fraction of over 0.6 is found downstream of the constriction. The minimum solver pressure of -4.4 bar is found near the beginning of the constriction and near the wall. The experimental image shows a liquid jet originating from the constriction. The pressure upstream is $8.9 \mathrm{bar}$, the pressure at the pressure port is 0.5 bar. A semi-cylindrical vapour pocket which fills the channel from top to bottom is visible just after the constriction. A dark region probably formed by vapour nuclei of sufficient size for discoloration is visible. After about $300 \mu \mathrm{m}$, the cavities break up and disappear. There is no flow through the pressure port 
is observed. Spherical oscillation and collapse of gas bubbles is not apparent in the images.

The calculated downstream pressure at the pressure port is 0.15 bar. This is in reasonable agreement with the experimental value of 0.5 bar. There is a long pressure recovery region of $625 \mu \mathrm{m}$ behind the constriction. It induces an excessive growth of the bubbles. The calculated void fraction profile qualitatively agrees with the experimental one. CFD calculations describe non-local phenomena such as the jet and average void fraction fairly well. The local phenomena such as the turbulent collapse of the vapour are not modelled in this approach with symmetry planes and steady state.

Excessive vapour formation occurs at the channel walls with liquid pressures close to the vapour pressure in case a surface nucleation term is included in the model. This does not match experimental observations and therefore the surface nucleation term has not been used in further calculations. The residence time and pressures obtained inside the constriction are sufficient to obtain growth of the nuclei. The surface tension delays the cavitation of a filtered liquid because growth of smaller bubbles needs a larger force than that of larger bubbles. Surface tension is not included in the cavitation model but its effect on the vapour formation can be modelled by lowering the pressure threshold for cavitation in Eq. 3 .

No measurable conversion has been observed in potassium iodide oxidation in the micro channel. Either there is no collapse with a hot spot, or the reaction is not sensitive enough to quantify the radical production. The bubble growth is excessive, filling the entire channel at some places. This prevents spherical collapse and high hot spot temperatures. Calculations with the full Rayleigh-Plesset model yield maximum bubble sizes which exceed the channel dimensions and are not suitable to estimate hot spot temperatures. Further experiments have therefore been carried out in a milli channel.

\subsection{Milli channel}

A ring of vapour is formed near the wall of the constriction as predicted by CFD calculations in the milli channel. Afterwards, the vapour is released into the chamber. The vapour volume fraction downstream of the constriction remains below 0.2 so no excessive bubble growth is expected in the chamber at any flow rate studied. The pressure recovery takes place inside the constriction which differs from microscale where the pressure recovery is observed downstream of the constriction (see Fig. 6a for examples).

Cavitation has been observed in the milli channel at relatively low flow rates of $7 \mathrm{~mL} \mathrm{~min}^{-1}\left(v_{c} 12 \mathrm{~m} \mathrm{~s}^{-1}\right)$ in the $110 \mu \mathrm{m}$ PMMA constriction with $p_{\mathrm{DS}}=1.1 \mathrm{bar}$, and a flow rate of $14 \mathrm{~mL} \mathrm{~min}^{-1}\left(v_{c} 9 \mathrm{~m} \mathrm{~s}^{-1}\right)$ in the $180 \mu \mathrm{m}$ PMMA constriction with $p_{\mathrm{DS}}=1.3$ bar. The shape of the vapour pockets is similar at all flow rates measured. Fig. $5 \mathrm{~b}$ shows a typical image of cavitation at a flow rate of $60 \mathrm{~mL} \min ^{-1}\left(v_{c} 39 \mathrm{~m} \mathrm{~s}^{-1}\right)$. Long gas pockets that extend over the entire length of the constriction are formed in the beginning of the constriction. These gas pockets are transparent and stable over time. The two-phase flow in the chamber forms a dark mist flow at flow rates around $30 \mathrm{~mL} \mathrm{~min}{ }^{-1}\left(v_{c} 20 \mathrm{~m} \mathrm{~s}^{-1}\right.$, not shown. A mist flow is visible in Fig. $5 b$ on the right side of the image). The mist flow likely comes from the many small nuclei that have grown to visible size in and just after the constriction. The many bubbles are observed as a mist because either the bubbles are too small for the resolution of the optics, because not all bubbles are in camera focus, because the light is shielded by the entire cloud of bubbles, due to motion blur, or a combination of these factors. The onset of cavitation can be seen in Fig. 5b, where the stable transparent gas pockets collapse in a turbulent region. Bubbles are ejected from the constriction at low flow rates in Fig. 5c. The features of the two-phase flow are not sharp, either due to motion blur or due to the size of the gas pockets, which may be too small to be resolved with the current set-up. A sharp crackling sound which is connected with the cavitation collapse has been detected at all flow rates mentioned. Visual confirmation of bubble oscillation has not been obtained due to the high flow velocities in the experiments.

The predicted ring of vapour inside the constriction is observed experimentally in Fig. 5b. The distinction between the experimental hydrodynamics of two-phase flow-whether a bubbly flow, or a mist flow is formedcannot be made from the CFD calculations. This is because the model does not consider single bubble interfaces, break-up and coalescence, but volume fractions as continuous variables. The characteristics of the collapse such as the hot spot temperature can not be directly calculated from the CFD calculations as a result. Therefore the full Rayleigh-Plesset Equations 7-9 have been solved for a bubble travelling along a streamline. The maximum temperature is estimated from the corresponding pressure gradients by Eqs. 7-9. The higher the temperature, the more radicals can be formed. An accurate description of the vapour formation is needed to obtain accurate pressure profiles.

In Fig. 6, the maximum temperature obtained by a bubble traveling along a pressure profile in a $180-\mu \mathrm{m}$ constriction is reported. The highest temperatures are obtained at the highest flow rate of $90 \mathrm{~mL} \mathrm{m^{-1 }}\left(\begin{array}{ll}v_{c} & 59\end{array}\right.$ $\mathrm{m} \mathrm{s}^{-1}$ ). This corresponds to the largest pressure drop of 40 bar (from 38 to -2 bar). The first nonlinear collapse yields a temperature of $3530 \mathrm{~K}$. This temperature is high 


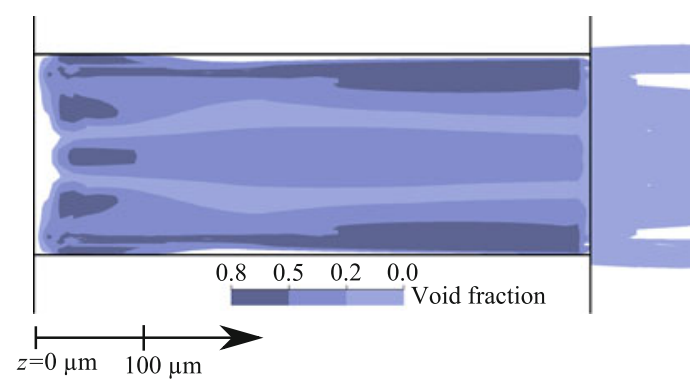

(a) CFD milli channel neck with a flow rate of $90 \mathrm{~mL} \mathrm{~min}^{-1}$ $\left(v_{c} 59 \mathrm{~m} \mathrm{~s}^{-1}\right)$

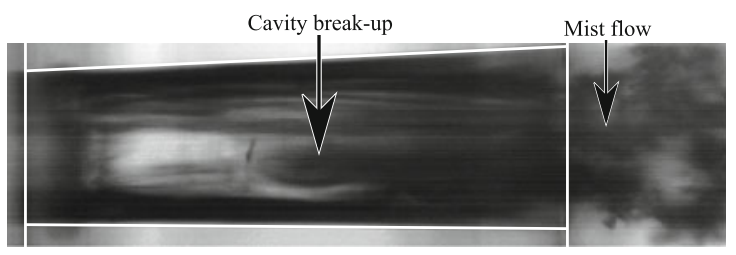

(b) Milli channel neck with a flow rate of $60 \mathrm{~mL} \mathrm{~min}^{-1}$ $\left(v_{c} 39 \mathrm{~m} \mathrm{~s}^{-1}\right)$

Fig. 5 Comparison of CFD simulation results of void fraction (a) and experimental image (b) of cavitation in a milli channel with a $180 \mu \mathrm{m}$ diameter constriction at a flow rate of $60 \mathrm{~mL} \mathrm{~min}^{-1}$, and an image of the chamber (c) at a flow rate of $20 \mathrm{~mL} \mathrm{~min}^{-1}$. Vapour formation takes place near the walls in the CFD calculation and reaches vapour fractions of 0.8. A liquid jet with lower vapour fractions is present in

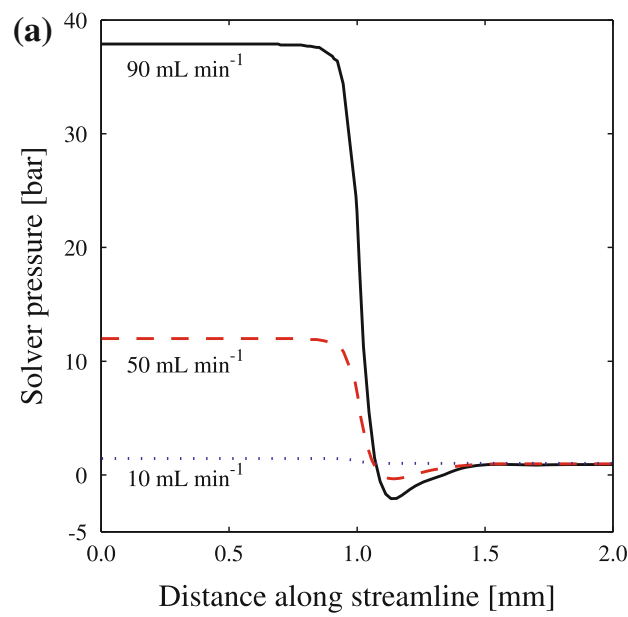

Fig. 6 Pressure gradients (a) and the temperature obtained by a Rayleigh-Plesset calculation (b) in the milli channel with the $180 \mu \mathrm{m}$ constriction. A gas bubble with initial radius of $5 \mu \mathrm{m}$ traveling near the pressure minimum at flow rates of $10-90 \mathrm{~mL} \mathrm{~min}^{-1}\left(v_{c}\right.$ $7-59 \mathrm{~m} \mathrm{~s}^{-1}$ ). The pressure drop from the beginning to the end of the channel is higher at higher flow rates, and ranges from $0.5-37$ bar (a). The constriction is marked by the sharp decrease in solver

enough for dissociation of chemical bonds in $\mathrm{CHCl}_{3}$ (Won and Bozzelli 1992). Calculations using Eqs. 7-10, a sinusoidal sound field with an amplitude of 1.3 bar at a frequency of $20 \mathrm{kHz}$, and an initial bubble radius of $5 \mu \mathrm{m}$ yield a maximum temperature of $5000 \mathrm{~K}$. The pressure drop at a flow rate of $30 \mathrm{~mL} \mathrm{~min}^{-1}\left(v_{c} 20 \mathrm{~m} \mathrm{~s}^{-1}\right)$ is

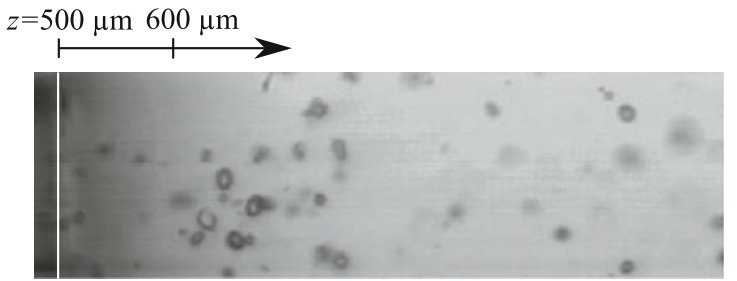

(c) Milli channel chamber with a flow rate of $20 \mathrm{~mL} \mathrm{~min}^{-1}$ $\left(v_{c} 13 \mathrm{~m} \mathrm{~s}^{-1}\right)$

the centre of the constriction. The experimental pressure downstream is 3.1 bar (b), and 1.5 bar (c). The constriction walls are outlined by white lines. Long straight vapour pockets are formed in the beginning of the constriction (b). Turbulent break-up of the vapour pockets takes places inside the constriction in this image (indicated with an arrow). Bubbly flow is created at a flow rate of $20 \mathrm{~mL} \mathrm{m^{-1 }}$ (c)

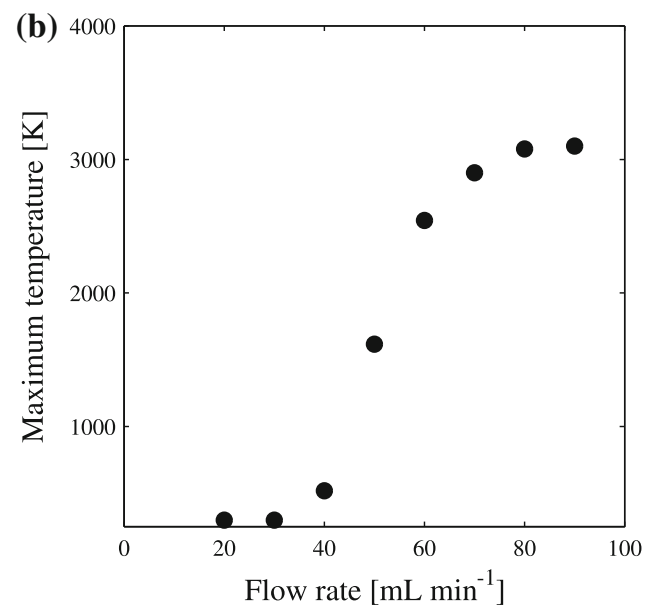

pressure, it reaches values as low as -2.1 bar, where the higher flow rates reach the lowest pressures. There is a quick recovery of the solver pressure to atmospheric values behind the pressure minimum. Progressively higher collapse temperatures are obtained at increasing flow rates (b) with a maximum of $3100 \mathrm{~K}$ at a flow rate of $90 \mathrm{~mL} \mathrm{~min}{ }^{-1}$. The collapse is linear and almost isothermal at a flow rate of $30 \mathrm{~mL} \mathrm{~min}^{-1}$

4.2 bar (from 4.8 to 0.6 bar), which is not sufficient to induce a nonlinear growth and collapse in a nucleus at any size investigated here. The hot spot temperatures obtained in the experiments are lower than those calculated for the single bubble travelling along the channel. This is because the presence of other bubbles distorts the sphericity of the 


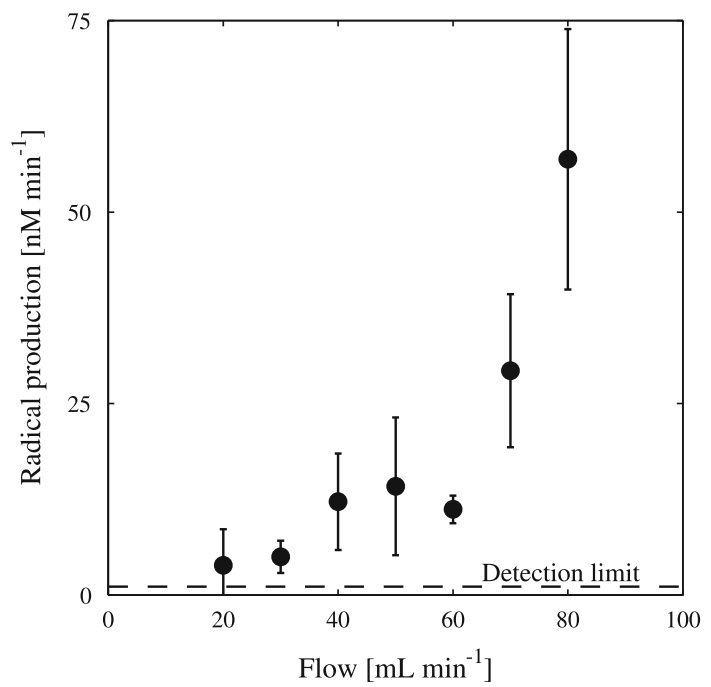

Fig. 7 Potassium iodide oxidation measurements in the milli channel using the $200 \mu \mathrm{m}$ diameter PEEK constriction at varying flow rates. A radical production of $4-60 \mathrm{nM} \mathrm{min}{ }^{-1}$ is observed for flow rates of 20-80 $\mathrm{mL} \mathrm{min}^{-1}$ ( $v_{c}$ 13-52 $\mathrm{m} \mathrm{s}^{-1}$ ) and a volume of $50 \mathrm{~mL}$. Error bars indicate one standard deviation. The detection limit is defined as three times the standard deviation of the noise of a blank measurement and is $1.1 \mathrm{nM} \mathrm{min}{ }^{-1}$

bubble during collapse, thereby decreasing the hot spot temperature.

Radical production rates of up to $60 \mathrm{nM} \mathrm{min}{ }^{-1}$ have been measured in the milli channel with a $200 \mu \mathrm{m}$ diameter constriction. Radical production increased with increasing flow rates. The $100 \mu \mathrm{m}$ diameter constriction yields a potassium iodide oxidation rate of $4-10 \pm 6 \mathrm{nM} \mathrm{min}^{-1}$ at flow rates between 25 and $35 \mathrm{~mL} \mathrm{~min}^{-1}\left(v_{c} \quad 44-61\right.$ $\mathrm{m} \mathrm{s}^{-1}$ ). No radical formation has been measured in the $300 \mu \mathrm{m}$ constriction at flow rates up to $100 \mathrm{~mL} \mathrm{m^{-1 }}\left(v_{c}\right.$ $\left.23 \mathrm{~m} \mathrm{~s}^{-1}\right)$. The maximum yield per unit energy of $5 \times 10^{-11} \mathrm{~mol} J^{-1}$ at a flow rate of $80 \mathrm{~mL} \mathrm{~min}^{-1}\left(v_{c}\right.$ $52 \mathrm{~m} \mathrm{~s}^{-1}$ ) in the $200 \mu \mathrm{m}$ constriction is in the same range as oxidation rates measured in other hydrodynamic cavitation experiments for this reaction, $3 \times 10^{-13}-8 \times$ $10^{-11} \mathrm{~mol} \mathrm{~J}^{-1}$ (Gogate et al. 2001), with energy measurements by calorimetry. The calculated values in Fig. 6 match the experimental results in Fig. 7 only qualitatively. At increasing flow rate, an increasing temperature is calculated and an increasing radical formation is measured. On the other hand, there is only a $22 \mathrm{~K}(0.7 \%)$ difference in temperature between the flow rates of 70 and $80 \mathrm{~mL} \min ^{-1}$ in the calculations, but a $94 \%$ difference in the potassium iodide oxidation measurements, which is not accounted for by an increase of only $12.5 \%$ in number of passes through the constriction at $90 \mathrm{~mL} \mathrm{~min}^{-1}$ as compared to $80 \mathrm{~mL} \mathrm{~min}{ }^{-1}$.

The residence time inside the $200 \mu \mathrm{m}$ constriction is $6.3 \mu \mathrm{s}$. This corresponds to an apparent frequency of the pressure field of $160 \mathrm{kHz}$, a value comparable to ultrasonic cavitation frequencies. It is therefore likely that discrepancies between hydrodynamic cavitation and ultrasonic cavitation are not created by a difference in frequency (Arrojo and Benito 2008) but by the difference in the pressure profiles perceived by the cavitation bubble. The pressure profiles are mainly governed by channel geometry and cloud formation. Also other factors in hydrodynamic cavitation, such as for example the turbulent break up of the vapour phase, may also affect the total oxidation yield (Moholkar and Pandit 1997). A higher radical production is expected in less constrained environments than the milli chamber, such as orifice plates with micro constrictions.

The CNs are presented in Table 3. They depend on the somewhat arbitrary choice of the reference pressure $p_{\text {ref }}$. The downstream pressure is often used as reference pressure. Cavitation inception is visually detected and is therefore arbitrarily determined. Very small or fast gas pockets may not be detected. The definition of cavitation inception is also inconsistent with the current understanding on how cavitation is initiated. Nuclei are present in the liquid and stabilised by either e.g. wall roughness, dust particles, or other impurities (Crum 1982). Cavitation is therefore a continuous rather than an instantaneous process. The liquid is filtered to prevent channel blocking in case of experiments with the micro channel. This has an impact on the distribution of nuclei in the liquid. The large distance of the pressure measurement from the constriction in the milli channel $(z=2.8 \mathrm{~cm})$ and the surface roughness of the PMMA constrictions may cause an artificially high $\mathrm{CN}$ in these experiments. The reason that size scale effects emerge is caused by lumping the influence of velocity and reference pressure into the $\mathrm{CN}$. The use of the $\mathrm{CN}$ as a defining parameter for cavitation is inconvenient when different geometries are compared.

Hybrid geometries with precisely manufactured micro constrictions with an unconfined exit offer opportunities to create high apparent frequencies and high radical

Table 3 Overview of experimental conditions in the cavitation visualisation experiments in the micro and milli channels, with minimum and maximum values obtained

\begin{tabular}{rlllllr}
\hline$d_{h}{ }^{\mathrm{a}}(\mu \mathrm{m})$ & $Q\left(\mathrm{~mL} \mathrm{~min}^{-1}\right)$ & $v_{c}\left(\mathrm{~m} \mathrm{~s}^{-1}\right)$ & $p_{\mathrm{DS}}$ bar & $\mathrm{CN}$ & $R e_{c}$ \\
\hline 33 & Min & 3.0 & 25 & $0.5^{\mathrm{b}}$ & 0.15 & 725 \\
& Max & 6.5 & 54 & $0.5^{\mathrm{b}}$ & 0.033 & 1,566 \\
110 & Min & 7 & 12 & $1.1^{\mathrm{c}}$ & 1.5 & 1,320 \\
& Max & 35 & 61 & $2.0^{\mathrm{c}}$ & 0.11 & 6,710 \\
180 & Min & 14 & 9 & $1.1^{\mathrm{c}}$ & 7.6 & 2,520 \\
& Max & 90 & 59 & $3.1^{\mathrm{c}}$ & 0.18 & 10,980 \\
\hline
\end{tabular}

\footnotetext{
${ }^{a}$ Hydraulic diameter

b Measured at $z=460 \mu \mathrm{m}$

c Measured at $z=2.8 \mathrm{~cm}$
} 
production rates. Also the study of plates with multiple constrictions is of interest since these can also give a higher radical production rate.

\section{Conclusions}

Void fraction distributions and pressure gradients in a hydrodynamically cavitating flow in a micro channel and milli channels have been modelled using CFD. Visualisation experiments yield a qualitative agreement with the void fractions obtained in CFD simulations in both size scales. A liquid jet and gas-liquid mixtures are visible in the micro channel, and formation of a bubbly flow or a mist flow in milli channels. The pressure profiles obtained from the CFD calculations have been used to give an estimation of the maximum gas temperature during the collapse using a full Rayleigh-Plesset cavitation model. A maximum temperature estimate of $3100 \mathrm{~K}$ at the maximum flow rate of $90 \mathrm{~mL} \mathrm{~min}{ }^{-1}\left(v_{c} 59 \mathrm{~m} \mathrm{~s}^{-1}\right)$ has been obtained. The real temperature obtained in the experiments is probably lower due to unsymmetrical collapse of the gas bubbles. An oxidation rate of potassium iodide in the presence of chloroform of up to $60 \mathrm{nM} \mathrm{min}{ }^{-1}$ has been measured in the $180 \mu \mathrm{m}$ diameter milli channel.

Acknowledgments The financial support by the Dutch Technology Foundation STW (project number 7391), Bunova, Intelligent Laser Applications, KWR, and Micronit is gratefully acknowledged. Joost Rooze thanks Madan (D.) Bindraban for the design of the milli chamber and Joost Velterop for lending equipment. David FernándezRivas thanks Dr. Yoav Peles for helpful discussion.

Open Access This article is distributed under the terms of the Creative Commons Attribution Noncommercial License which permits any noncommercial use, distribution, and reproduction in any medium, provided the original author(s) and source are credited.

\section{References}

Alehossein H, Qin Z (2007) Numerical analysis of Rayleigh-Plesset equation for cavitating water jets. Int $\mathrm{J}$ Numer Methods Eng 72(7):780-807. doi:10.1002/nme.2032

Amin LP, Gogate PR, Burgess AE, Bremner DH (2010) Optimization of a hydrodynamic cavitation reactor using salicylic acid dosimetry. Chem Eng J 156(1):165-169. doi:10.1016/j.cej. 2009.09.043

Arrojo S, Benito Y (2008) A theoretical study of hydrodynamic cavitation. Ultrason Sonochem 15(3):203-211. doi:10.1016/j. ultsonch.2007.03.007

Beckett MA, Hua I (2001) Impact of ultrasonic frequency on aqueous sonoluminescence and sonochemistry. J Phys Chem 105:37963802. doi:10.1021/jp003226x

Braeutigam P, Wu ZL, Stark A, Ondruschka B (2009) Degradation of BTEX in aqueous solution by hydrodynamic cavitation. Chem Eng Technol 32(5):745-753. doi:10.1002/ceat.200800626
Braeutigam P, Franke M, Wu ZL, Ondruschka B (2010) Role of different parameters in the optimization of hydrodynamic cavitation. Chem Eng Technol 33(6):932-940. doi:10.1002/ceat. 201000021

Chakinala AG, Gogate PR, Chand R, Bremner DH, Molina R, Burgess AE (2008) Intensification of oxidation capacity using chloroalkanes as additives in hydrodynamic and acoustic cavitation reactors. Ultrason Sonochem 15(3):164-170. doi: 10.1016/j.ultsonch.2007.02.008

Crum LA (1982) Nucleation and stabilization of microbubbles in liquids. Appl Sci Res 38(1):101-115. http://dx.doi.org/10.1007/ BF00385941

Didenko YT, Suslick KS (2002) The energy efficiency of formation of photons, radicals and ions during single-bubble cavitation. Nature 418(6896):394-397. http://dx.doi.org/10.1038/nature 00895

Esch T, Menter FR (2003) Heat transfer prediction based on twoequation turbulence models with advanced wall treatment. In: Hanjalic K, Nagano Y, Tummers M (eds) Proceedings of turbulence, heat and mass transfer IV, Begell House Inc

Fernandez Rivas D, Prosperetti A, Zijlstra AG, Lohse D, Gardeniers JGE (2010) Efficient sonochemistry through microbubbles generated with micromachined surfaces. Angew Chem, Int Ed 49:9699-9701. doi:10.1002/anie.201005533

Franke M, Braeutigam P, Wu ZL, Ren Y, Ondruschka B (2010) Enhancement of chloroform degradation by the combination of hydrodynamic and acoustic cavitation. Ultrason Sonochem 18(4): 888-894. doi:10.1016/j.ultsonch.2010.11.011

Gogate PR (2010) Hydrodynamic cavitation for food and water processing. Food Bioproc Technol 3:1-16. doi:10.1007/s11947010-0418-1

Gogate PR, Shirgaonkar IZ, Sivakumar M, Senthilkumar P, Vichare NP, Pandit AB (2001) Cavitation reactors: efficiency assessment using a model reaction. AIChE J 47(11):2526-2538. doi: 10.1002/aic.690471115

Hilgenfeldt S, Grossmann S, Lohse D (1999) Sonoluminescence light emission. Phys Fluids 11(6):1318-1330. doi:10.1063/1.869997

Kalamuck KM, Chahine GL (2000) The use of cavitating jets to oxidize organic compounds in water. J Fluids Eng 122:465-470. doi:10.1115/1.1286993

Kamath V, Prosperetti A, Egolfopoulos FN (1993) A theoretical study of sonoluminescence. J Acoust Soc Am 94(1):248-260. doi: $10.1121 / 1.407083$

Leighton TG (1994) The acoustic bubble. Academic Press, London

Löfstedt R, Weninger K, Putterman S, Barber BP (1995) Sonoluminescencing bubbles and mass diffusion. Phys Rev E 51(5): 4400-4410. doi: 10.1103/PhysRevE.51.4400

Marmottant P, Versluis M, de Jong N, Hilgenfeldt S, Lohse D (2006) High-speed imaging of an ultrasound-driven bubble in contact with a wall: "Narcissus" effect and resolved acoustic streaming. Exp Fluids 41:147-153. doi:10.1007/s00348-005-0080-y

Mason TJ (1990) Sonochemistry: the uses of ultrasound in chemistry. Royal Society of Chemistry Cambridge

McNamara WB III, Didenko YT, Suslick KS (1999) Sonoluminescence temperatures during multi-bubble cavitation. Nature 401(6755):772-775. doi:10.1038/44536

Mishra C, Peles Y (2005a) Cavitation in flow through a micro-orifice inside a silicon microchannel. Phys Fluids 17(1):013601. doi: $10.1063 / 1.1827602$

Mishra C, Peles Y (2005b) Flow visualization of cavitating flows through a rectangular slot micro-orifice ingrained in a microchannel. Phys Fluids 17(11):113602. doi:10.1063/1.2132289

Mishra C, Peles Y (2005c) Size scale effects on cavitating flows through microorifices entrenched in rectangular microchannels. J Microelectromech S 14(5):987-999. doi:10.1109/JMEMS. 2005.851800 
Moholkar VS, Pandit AB (1997) Bubble behavior in hydrodynamic cavitation: Effect of turbulence. AIChE J 43(6):1641-1648. doi: 10.1002/aic.690430628

Palmer DA, Ramette RW, Mesmer RE (1984) Triiodide ion formation equilibrium and activity coefficients in aqueous solution. J Solut Chem 13(9):673-683. doi:10.1007/BF00650374

Rae J, Ashokkumar M, Eulaerts O, von Sonntag C, Reisse J, Grieser F (2005) Estimation of ultrasound induced cavitation bubble temperatures in aqueous solutions. Ultrason Sonochem 12(5): 325-329. doi:10.1016/j.ultsonch.2004.06.007

Singh R, Peles Y (2009) The effects of fluid properties on cavitation in a micro domain. J Micromech Microeng 19(2):025,009. doi: 10.1088/0960-1317/19/2/025009

Suslick KS, Price GJ (1999) Applications of ultrasound to materials chemistry. Annu Rev Mater Sci 29(1):295-326. doi:10.1146/ annurev.matsci.29.1.295
Suslick KS, Mdleleni MM, Ries JT (1997) Chemistry induced by hydrodynamic cavitation. J Am Chem Soc 119(39):9303-9304. doi:10.1021/ja972171i

Wayment DG, Casadonte DJ Jr (2002) Design and calibration of a single-transducer variable-frequency sonication system. Ultrason Sonochem 9(4):189-195. doi:10.1016/S1350-4177(01)00127-4

Won YS, Bozzelli JW (1992) Chloroform pyrolysis: experiment and detailed reaction model. Combust Sci Technol 85(1):345-373

Yan Y, Thorpe RB (1990) Flow regime transitions due to cavitation in the flow through an orifice. Int J Multiph Flow 16(6):1023-1045. doi:10.1016/0301-9322(90)90105-R 